\title{
North Atlantic Multidecadal SST Oscillation: External forcing versus internal variability
}

\author{
Mingfang Ting *, Yochanan Kushnir, Cuihua Li \\ Lamont-Doherty Earth Observatory, Columbia University, United States
}

\section{A R T I C L E I N F O}

\section{Article history:}

Received 16 March 2012

Received in revised form 7 July 2013

Accepted 13 July 2013

Available online 27 July 2013

\section{Keywords:}

Climate

Atlantic Multidecadal Oscillation

Anthropogenic forcing

Internal variability

\begin{abstract}
A B S T R A C T
The Atlantic Multi-decadal Oscillation (AMO) depicts the swings of North Atlantic basin-wide sea surface temperature (SST) between warm and cold phases on a multi-decadal time scale. The 20th Century instrumental record indicates a relative cold period in the beginning of the 20th Century, a warm period in the 1940s and 50s, another cold period in the 1970s and 80s, followed by the recent warming period. These multi-decadal temperature swings coincide with an upward warming trend throughout the 20th Century. One of the central questions concerning these changes is whether they were caused by human activities, including aerosols and greenhouse gas forcing, or whether they reflect some combination between natural factors and human activity. Using both observations and CMIP3 model simulations, we argue that the overall changes are due to the combination of natural multidecadal variability and anthropogenic forcing. We also examine the regional surface temperature, precipitation, and atmospheric circulation features associated with the externally forced and internal North Atlantic SST multidecadal variability using both 20th Century observations and CMIP3 model simulations of the 20th, 21st, and pre-industrial forcing.
\end{abstract}

(c) 2013 Elsevier B.V. All rights reserved.

\section{Introduction}

The Atlantic Multidecadal Oscillation (AMO) represents a basin scale mode of variability in North Atlantic sea surface temperature (SST). The instrumental record is not long enough to determine if the phenomenon is truly oscillatory and this is why it is sometimes referred to as Atlantic Multidecadal Variability (AMV). However, using the instrumental records of the past 130 years, the "period" of the AMO is estimated to be $60-80$ years (e.g., Schlesinger and Ramankutty, 1994). Reconstructions of the AMO based on paleoproxy suggest that the AMO period varies across a range of scales (Delworth and Mann, 2000; Gray et al., 2004; Knudsen et al., 2011).

The complexity in understanding the mechanisms and impacts of the observed AMO stems, in part, from its concurrence with the century-long, generally upward trend in North Atlantic SST, a trend that is possibly associated with the increase in global surface temperature attributed to anthropogenic forcing. By inferring the forced climate response using the ensemble mean Coupled Model Intercomparison Project phase 3 (CMIP3) models, Knight (2009) concluded that the observed AMO is inconsistent with the notion that it is a forced climate response, thus supporting the existence of an unforced component of the AMO. Ting et al. (2009) used the CMIP3's multi-model/multi-ensemble 20th Century simulations to estimate the radiatively forced North Atlantic SST trend and confirmed that the multi-decadal SST variability

\footnotetext{
* Corresponding author at: Lamont-Doherty Earth Observatory, 61 Rt. 9W, Palisades, NY 10964, United States. Tel.: + 1845365 8374; fax: + 18453658736.

E-mail address: ting@ldeo.columbia.edu (M. Ting). Lamont Contribution Number: 7713.
}

over the North Atlantic in 20th Century observations is well outside of the range of forced variability, consistent with the results of Knight (2009). Ting et al (2009) have further shown that the spatial structures of the forced and internal North Atlantic SST variability patterns are distinctly different from each other and each tied to unique worldwide precipitation anomalies. A more recent study by DelSole et al. (2010) argues that there exists a global pattern of internal multidecadal variability, separable from the anthropogenic signal and centered in the North Atlantic and North Pacific and that it contributed significantly to the global warming trend of the recent decades (1977-2008). This further emphasizes the necessity to separate between and accurately account for the forced and internal SST patterns of variability in the North Atlantic. Ting et al. (2011) examined further the robust patterns of the AMO in observations and CMIP3 simulations with various greenhouse and aerosol forcing scenarios, from pre-industrial to 21st Century A1b scenario, and concluded that the AMO is a mode of the coupled ocean-atmosphere system that is independent of external radiative forcing.

While the work discussed above advocates a role for unique internal mechanisms in creating the AMO, others have advocated the dominance of external forcing, at least as far as the 20th century variability is concerned. Mann and Emmanuel (2006), who focused on the tropical Atlantic sector, raised the possibility that the multi-decadal, Atlanticcentered SST variability in observations is entirely radiatively forced by a combination of greenhouse gas warming and cooling caused by industrial and volcanic aerosols. A recent study (Booth et al., 2012), using the Hadley Center Global Environmental Model version 2 Earth System (HadGEM2-ES) with and without natural and anthropogenic aerosol forcing, argued that the 20th Century North Atlantic SST 
fluctuations are primarily forced by the direct and indirect aerosol radiative effects, contrary to the many previous studies that emphasize the role of internal ocean-atmosphere processes. Zhang et al. (2013) disputed the Booth et al. (2012) results by comparing a broad spectrum of observed and HadGEM2-ES model-simulated variables in addition to SST, and concluded that while the SST signal in the HadGEM2-ES results does indicate a large contribution of aerosols to 20th century AMO, there are large discrepancies between this simulation and observations resulting from the excessively strong and unrealistic aerosol indirect effects in that model. The issue of the role of aerosols in forcing the observed AMO thus remains an open question, one that will not be directly addressed in the current study. It should be emphasized however, that the analysis method used in this study, described in more details below, does take into account aerosol forcing as represented by pooling all models that participated in CMIP3.

This study extends that of Ting et al. (2009) and examines the relevant circulation and precipitation patterns and their seasonality associated with the forced and natural North Atlantic SST variability using both observations and CMIP3 models. The focus is on those features that are potentially relevant for fishery and coastal ecosystems such as the sea level pressure patterns, surface wind, and precipitation. The central issues are whether the forced and internal variability are separable, and if so, how do they differ in both spatial and temporal characteristics of their climate impacts.

\section{Data and methods}

The observed sea surface temperature (SST) used in this study is from the Goddard Institute for Space Studies (GISS) analysis of global surface temperature change (Hansen et al., 2010), which uses the HadISST1 (Rayner et al., 2003) from 1880 to 1981 and satellite measurements of SST from 1982 to the present (OISST.v2) (Reynolds et al., 2002). The global land precipitation and surface air temperature were taken from the UEA CRU TS2p1 monthly datasets with $0.5^{\circ} \times 0.5^{\circ}$ resolutions (Mitchell and Jones, 2005).

The sea level pressure (SLP), surface wind, and 500 hpa geopotential height for observations are taken from the 20th Century reanalysis project (Compo et al., 20011) for the entire 20th Century.

In addition to the above observational datasets, we use outputs from the coupled ocean-atmosphere models used in the fourth assessment report of the Intergovernmental Panel on Climate Change (IPCC AR4) and the Climate Model Intercomparison Project phase 3 (CMIP3) organized by the World Climate Research Program (WCRP). A list of models and their corresponding ensemble members/length of integrations used in this study are shown in Table 1. We used four different types of simulations from CMIP3, the 20th Century forcing runs, which are forced with the observed solar, greenhouse gas and aerosol forcing during the 20th Century, the 21st Century A1B scenario runs, which is forced with the projected greenhouse gases and aerosol forcing for the 21st Century according to the A1B scenario, the 1\%/year CO2 increasing experiment, which applies a gradual increase in greenhouse gas concentration but no aerosol forcing, and the pre-industrial run that has the fixed amount of $\mathrm{CO} 2$ at the pre-industrial level. A total of 23 models and 75 (54) ensemble members were used for the 20th (21st) Century simulations, while 20 models were available and used for the $1 \% /$ year and pre-industrial simulations. In the cases of the 20th, 21st Century simulations where the same model is used to generate multiple integrations, the radiative forcing remains the same for all ensemble members, but the initial condition differs slightly, allowing the integrations to deviate from each other due to internal atmospheric and oceanic variability, which by definition is temporally uncorrelated between ensemble members. Thus when averaged across the ensemble members, internal variability will be significantly reduced and the forced signal can be closely estimated from the ensemble average.

Following previous studies (Ting et al., 2009, 2011), the signal-tonoise ratio maximizing empirical orthogonal function analysis $(\mathrm{S} / \mathrm{N}$
Table 1

Summary of CMIP3 models and corresponding ensemble members (or years of integration) used in the paper.

\begin{tabular}{lcccc}
\hline Models & 20th Century & $\begin{array}{l}21 \text { st Century } \\
(\mathrm{A} 1 \mathrm{~b})\end{array}$ & $\begin{array}{l}1 \% / \mathrm{year} \text { CO2 } \\
\text { Pre-industrial } \\
\text { (yrs) }\end{array}$ \\
\hline BCCR BCM2.0 & 1 & 1 & 1 & 250 \\
CCCMA CGCM3.1 & 5 & 5 & 1 & 601 \\
CCCMA CGCM3.1 T63 & 1 & 1 & 0 & 350 \\
CNRM CM3 & 1 & 1 & 1 & 300 \\
CSIRO MK3.0 & 3 & 1 & 1 & 380 \\
CSIRO MK3.5 & 3 & 1 & 1 & 600 \\
GFDL CM2.0 & 3 & 1 & 1 & 500 \\
GFDL CM2.1 & 5 & 1 & 1 & 500 \\
GISS AOM & 2 & 2 & 0 & 251 \\
GISS EH & 5 & 3 & 1 & 0 \\
GISS ER & 9 & 5 & 0 & 500 \\
INGV ECHAM4 & 1 & 1 & 1 & 0 \\
INMCM3.0 & 1 & 1 & 1 & 330 \\
IPSL CM4 & 1 & 1 & 1 & 500 \\
MIROC3.2 HIRES & 1 & 1 & 1 & 0 \\
MIROC3.2 MEDRES & 3 & 3 & 1 & 500 \\
MIUB ECHO G & 5 & 3 & 1 & 341 \\
MPI ECHAM5 & 4 & 4 & 1 & 506 \\
MRI CGCM2.3 & 5 & 5 & 1 & 350 \\
NCAR CCSM3.0 & 8 & 7 & 1 & 500 \\
NCAR PCM1 & 4 & 4 & 1 & 589 \\
UKMO HADCM3 & 2 & 1 & 1 & 342 \\
UKMO HADGEM1 & 2 & 1 & 1 & 240 \\
ALL & 75 & 54 & 20 & 20 \\
\hline
\end{tabular}

EOF) was used in this study to better extract the radiatively forced signal from the CMIP3 multi-model ensembles. The S/N EOF analysis entails a procedure that pre-whitens the raw model output data by first estimating the internal climate "noise" patterns from EOFs of the pre-industrial integrations (Allen and Smith, 1997). This pre-whitening procedure helps remove the internal variability that may be left in the multimodel ensemble average due to insufficient sampling and thus better extracts the forced patterns due to the common forcing applied in all model experiments.

\section{Forced North Atlantic SST Variability}

The observed annual mean North Atlantic SST index, which is the North Atlantic basin-wide average SST from the equator to $60^{\circ} \mathrm{N}$, is plotted in Fig. 1. A Butterworth low-pass filter with a cutoff frequency of 10 years was applied to the annual mean observations and is shown in red in the same figure but no other detrending procedure was used. In addition to residual interannual fluctuations, the index displays a large amplitude swing on multi-decadal time scales superimposed on a general upward trend throughout the record. Fig. 1b shows a tropical Atlantic SST index: SST averaged over the so-called Main Development Region (MDR, 6-18 N, 20-60 W) for the hurricane season (August, September and October). Are multidecadal fluctuations and trends in Fig. 1 forced responses to external forcing, i.e., anthropogenic and/or natural radiative forcing, or a manifestation of the internal ocean-atmosphere variability on multidecadal time scales? Given that the instrumental record is rather short with respect to the time scale of the fluctuation and the uncertainty in the radiative forcing during the 20th Century, one cannot conclusively state that there is a naturally occurring multi-decadal oscillation underlying the general warming trend. To address this question, we used climate model simulations in the 20th and 21st Centuries to help distinguish between the forced and natural components of the multidecadal SST variability in this study.

The S/N EOF analysis was first applied to annual mean low-pass (Butterworth filter with 10 year cutoff frequency) filtered North Atlantic SST $\left(0^{\circ}-60^{\circ} \mathrm{N}\right)$ using outputs from the multi-model, multiensemble members of the CMIP3 simulations of the 20th and 21st centuries. There were 23 models with a total of 75 multi-model 

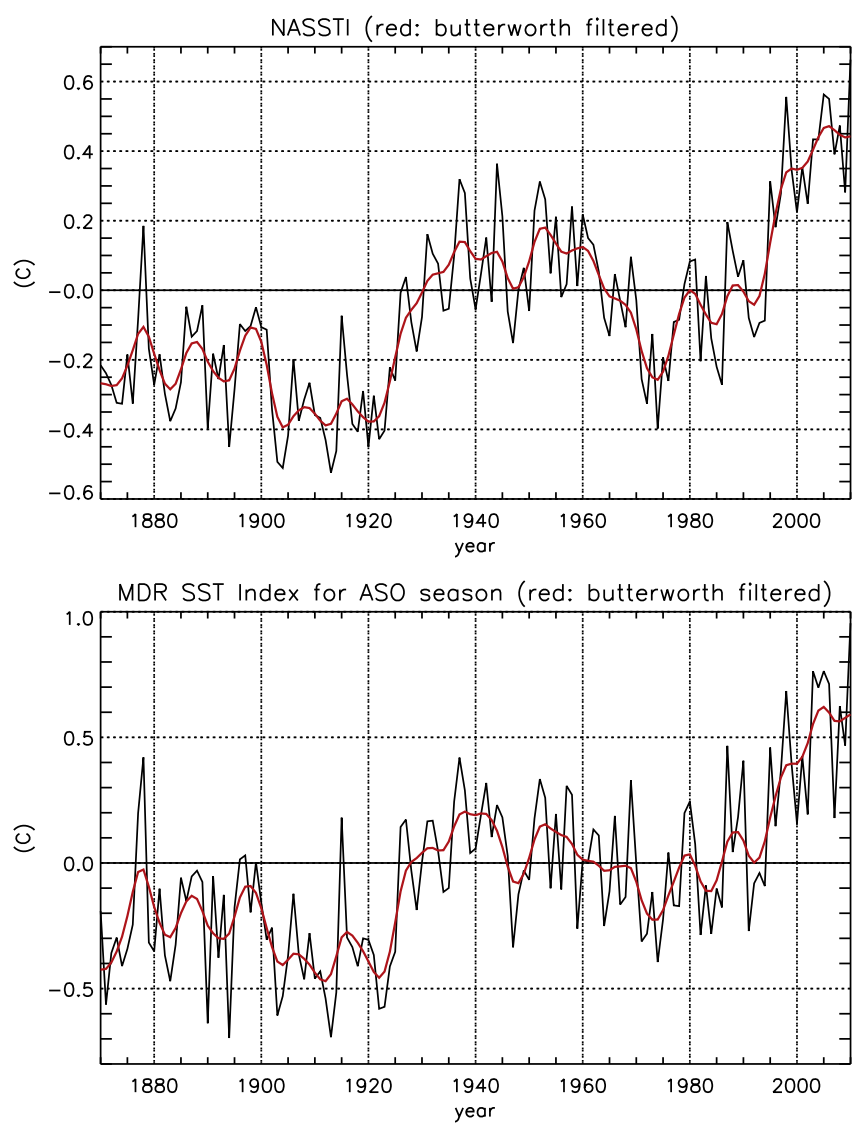

Fig. 1. (top) Annual Mean North Atlantic SST index using HadiSST averaged from equator to $60 \mathrm{~N}$ over the Atlantic basin and (bottom) the August, September, and October seasonal mean SST index averaged over the Main Development Region of the tropical North Atlantic $\left(10^{\circ} \mathrm{N}\right.$ to $20^{\circ} \mathrm{N}$ and $20^{\circ} \mathrm{W}$ to $\left.80^{\circ} \mathrm{W}\right)$.

Regression of SST onto S/N EOF PC1 (23 models, 20th Century)
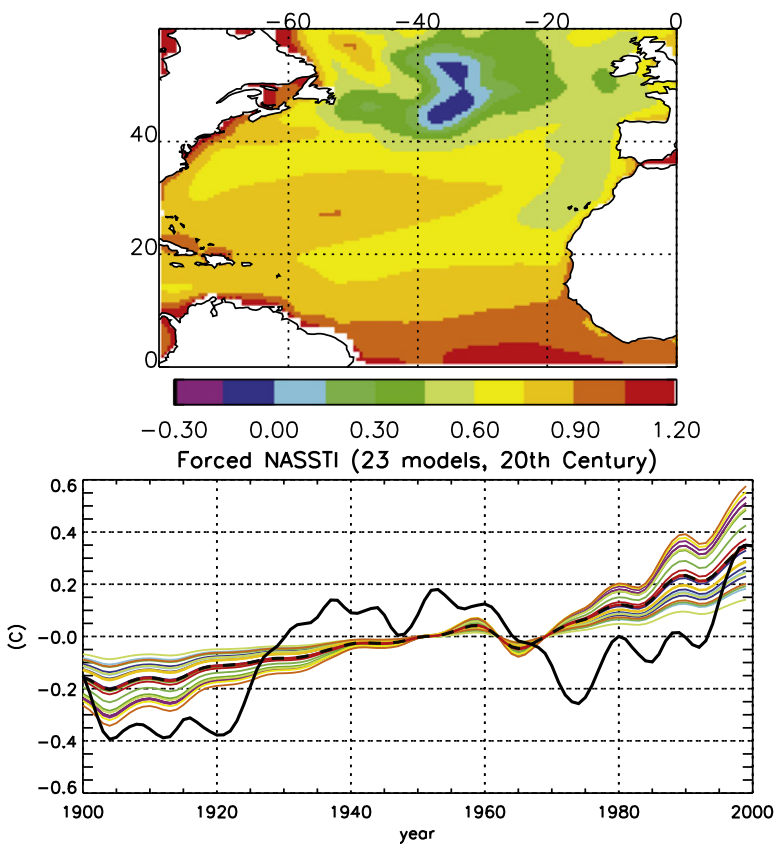

ensemble members for the 20th and 54 for the 21st century A1B scenario (see Table 1). Fig. 2 shows the spatial pattern (top) and temporal variations (bottom) of the S/N EOF1 for the 20th (left) and 21st (right) centuries. These patterns explain $91 \%$ and $97 \%$ of the total forced variance for the 20th and the 21st centuries, respectively, and thus represent well the total forced signal associated with the external radiative forcing. The S/N EOF1 is characterized by a cooling in northern North Atlantic, just south of Greenland, and warming in the rest of the basin in both centuries (top panels in Fig. 2). The spatial patterns of the 20th and the 21st centuries are very similar, with an area-weighted spatial pattern correlation of 0.89 (amplitude shown are in arbitrary units). The time series associated with this mode are represented in each model's basin average SST projection onto the EOF1 time series, as shown in colored lines (bottom panels of Fig. 2). The multi-model average EOF1 time series is shown in black dashed line and the observed 20th Century basinaverage SST time series is shown in the solid black line. The 21st Century time series (bottom right) exhibits an almost linear increase common to all models, while the corresponding 20th Century time series display some deviations from the linear curve, with a slower increase in the first few decades of the century and a faster increase in the last three decades of the 20th Century. In addition, these time series also show noticeable decadal variations. However, when compared to the observed 20th Century North Atlantic SST variations (solid black line), it is clear that the forced decadal variations in the model time series are much weaker than what has been observed. The monotonic, near linear increases of the forced North Atlantic SSTs associated with S/N EOF1 is consistent with forcing by external radiative changes due to both anthropogenic and natural (solar and volcanic) causes. There is a spread in amplitudes of the rate of change of the forced North Atlantic SST increases in different models, ranging from roughly $0.25^{\circ}-0.8^{\circ} \mathrm{C}$ per century for the 20th and from $1^{\circ}$ to $3^{\circ} \mathrm{C}$ per century for the 21 st Century. The spreads are likely due to differences in the model sensitivity to external forcing.

Some of the deviations from a linear increase in North Atlantic SST in 20th Century are consistent with previous studies on the effect of volcanic aerosols (e.g., Ch. 9 in Solomon et al., 2007; Meehl et al., 2004), smoothed
Regression of SST onto S/N EOF PC1 (23 models, 21st Century)
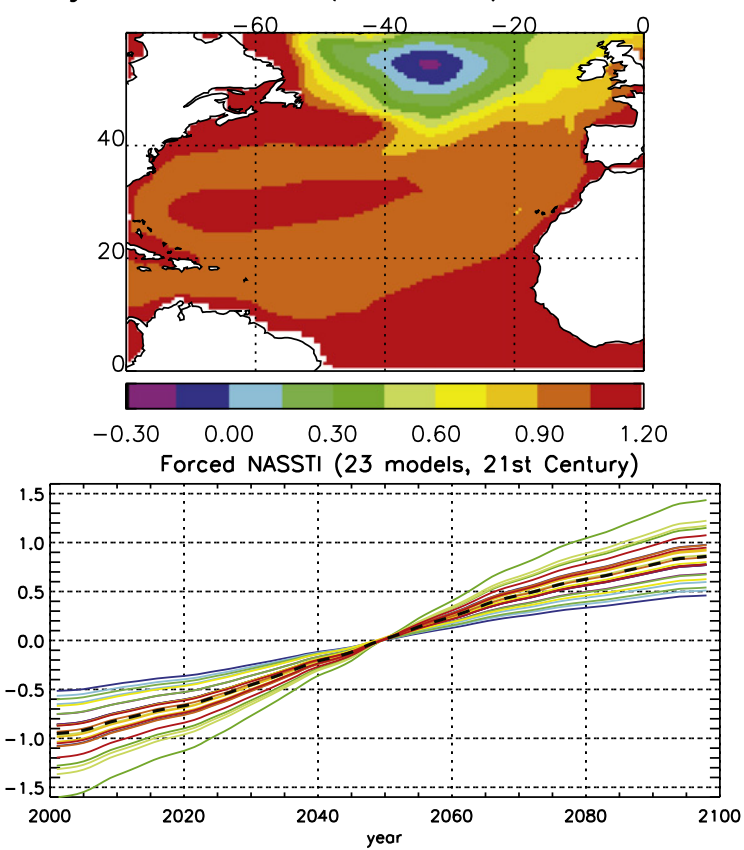

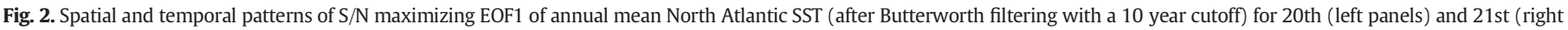

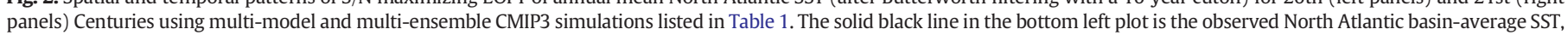
and the dashed black line in bottom panels are for model averages of the EOF1 time series. 
out due to the low-pass filtering applied prior to the EOF calculation. The cooling due to anthropogenic aerosols for the period $1950-80$ shows as a small dip in SST. To test the idea that there may be enhanced regional aerosol effect over the tropical North Atlantic as pointed out by Mann and Emannuel (2006), we performed another S/N EOF analysis using only the MDR regional SST for the season August, September and October (the choice of ASO season is for its correspondence to peak hurricane activities). Both the spatial patterns and temporal variations (not shown) are very similar to those shown in Fig. 2, with a slightly stronger decline in MDR SST for the period $1950-80$ (about $0.2{ }^{\circ} \mathrm{C}$ ), which is still smaller than what has been observed during the same period.

To illustrate the climate responses associated with the forced North Atlantic SST variability, we regressed annual mean fields of the global surface temperature and precipitation in the models onto the corresponding

Regression of TS onto Forced Component (a) Observations

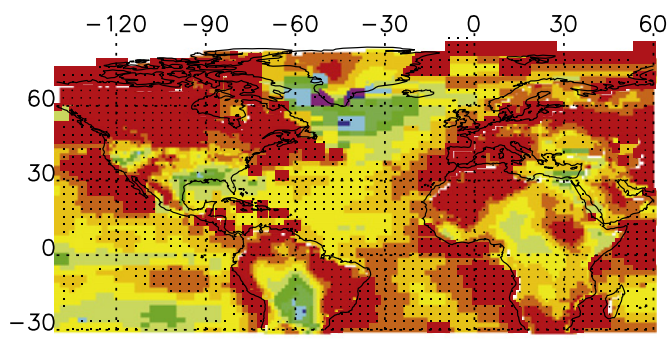

(b) 20th Century

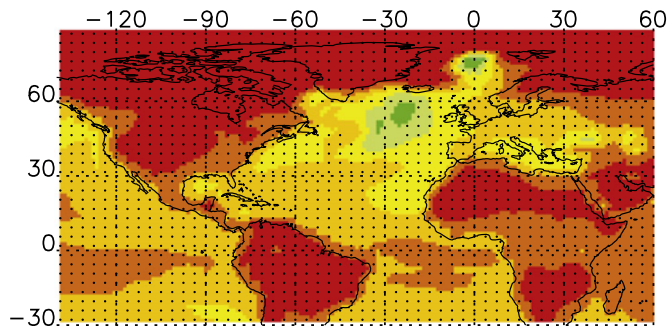

(c) $21 \mathrm{st}$ Century

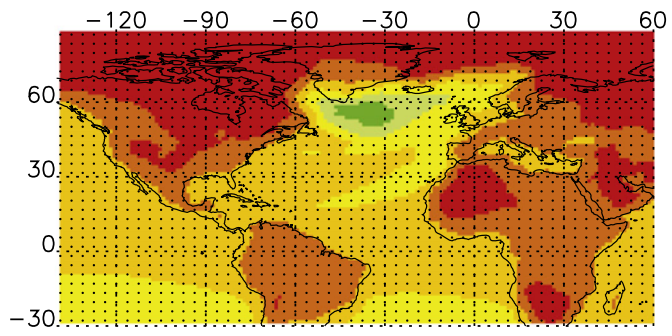

(d) 1 pctto2x

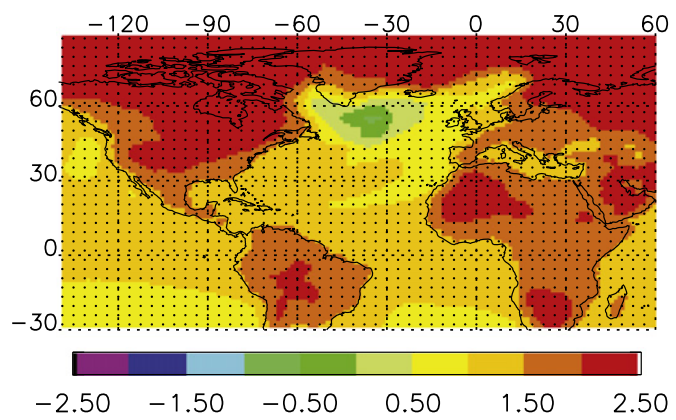

model forced time series (colored lines in Fig. 2). We then averaged the model regression patterns to obtain the multi-model average. This procedure was repeated for 20th and 21st Century CMIP3 simulations. For the observations, we regressed the observed annual mean fields on the multimodel averaged time series (the black dashed line in Fig. 2). The resulting patterns are shown in Fig. 3 (left panels for temperatures and right panels for precipitation). We stippled regions of $5 \%$ significance using a Monte Carlo bootstrapping method in the observational plot, and regions of model consistency (as explained in figure captions) in the model simulations. Although Fig. 3 does not show the global domain for the focus of this study on the North Atlantic and its vicinity, the regressed global surface temperature patterns are consistent with what is expected from global warming, with warming over most of the regions except small patches of cooling (or less warming) in the northern North Atlantic. Many

\section{Regression of $\operatorname{Pr}$ onto Forced Component}

\section{(e) Observations}

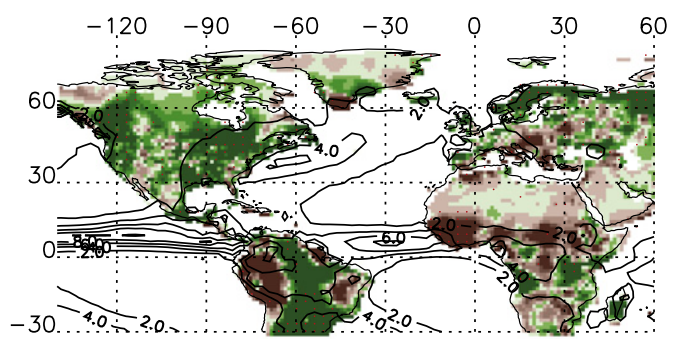

(f) 20th Century

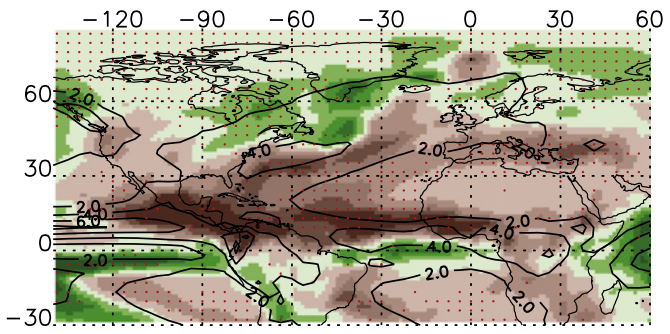

(g) $21 \mathrm{st}$ Century

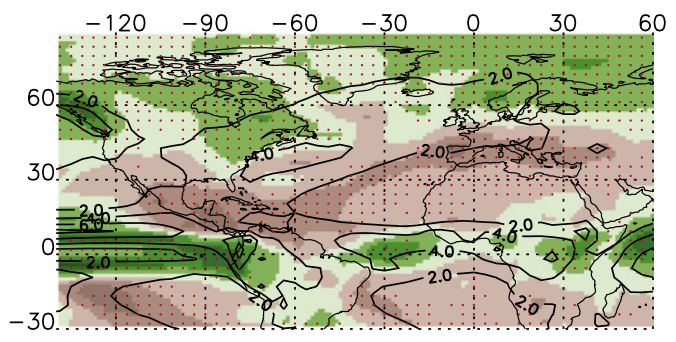

(h) 1 pctto2x

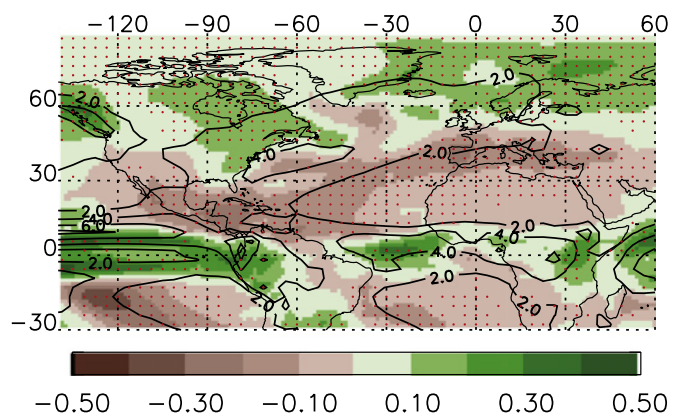

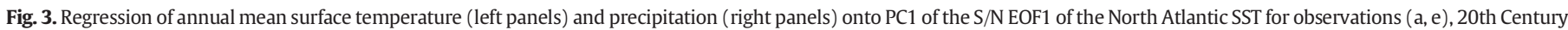

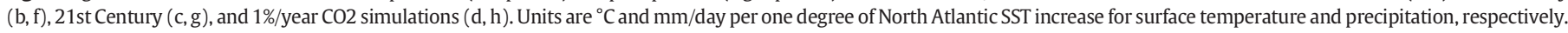

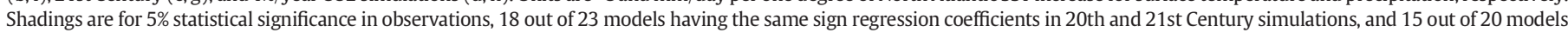
having the same sign of regression coefficients in 1\%/year CO2 experiments. 
previous modeling simulations of the transient response to $\mathrm{CO}_{2}$ increases have found a minimum in warming, or weak cooling, in the northern North Atlantic and have attributed it to the reduction in the ocean meridional overturning circulation and an associated reduction in heat transport into this region (Holland and Bitz, 2003; Meehl et al., 1996; Russell and Rind, 1999; Wood et al., 1999). All land surfaces show pronounced warming, with the exception of Central South America in observations where a cooling is found that may be due to data quality. There is also an indication of a weak cooling over southeastern U. S. in the 20th Century observations. The models, however, support a more uniform land warming globally. Note that the North Atlantic does not show a uniform warming as a response to external radiative forcing (left panels in Fig. 3), as one would expect from the AMO SST pattern (Ting et al., 2011 and Fig. 2 of Alexander et al., 2014-this volume).

In the associated precipitation patterns, there is pronounced subtropical drying (Held and Soden, 2006), particularly in the region extending from southwestern United States to northern Africa and the Mediterranean in both the 20th and 21st centuries model simulations. In the Southern Hemisphere, significant drying occurs in the eastern South Pacific and tropical South Atlantic. The drying in the southwestern U.S. is less obvious in observations, yet the models and observations have a reasonable agreement over other land regions, particularly over the Sahel region in the 20th Century. In high latitudes, there is enhanced precipitation due to increased moisture convergence associated with increased low-level moisture due to the greenhouse warming (Held and Soden, 2006). The

\section{Regression of $\mathrm{Pr}$ onto Forced Component(NDJF)}

\section{(a) Observations}

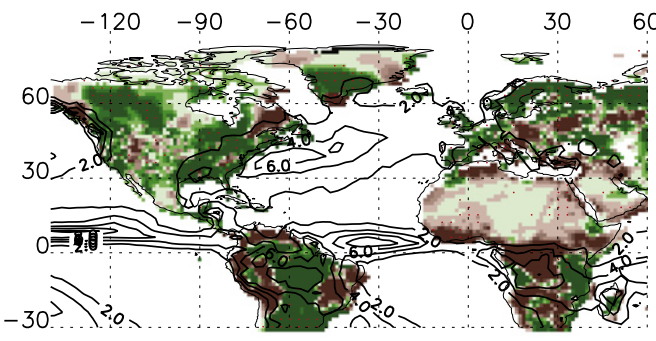

(b) 20th Century

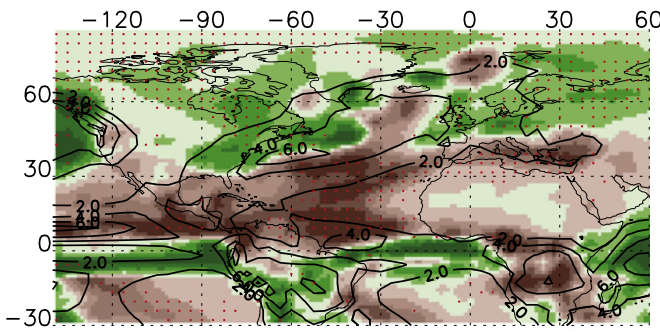

(c) 21st Century

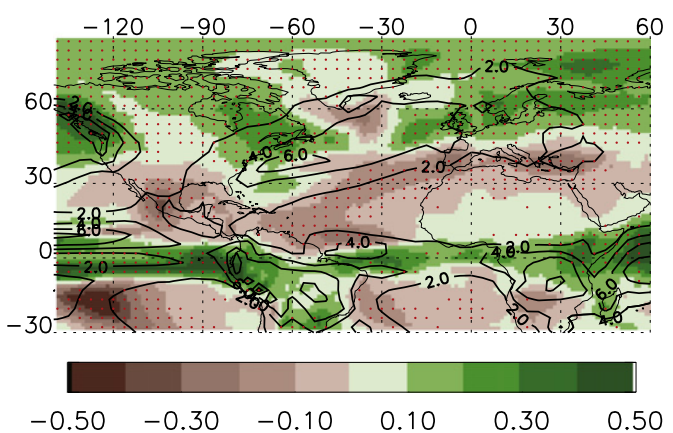

precipitation patterns associated with external radiative forcing are consistent with the IPCC AR4 results based on multi-model means (See Chapter 10, Solomon et al., 2007).

The amplitude of the precipitation change per degree $\mathrm{C}$ of Atlantic SST warming in Fig. 3 seems larger in the 20th than that in the 21st Century CMIP3 simulations. There are two plausible reasons for this discrepancy. The first reason is forcing by anthropogenic and volcanic aerosols during the 20th Century, which is missing in the 21st century simulations. The other reason is the increasing $\mathrm{CO}_{2}$ forcing strength in the 21st Century. To explore these possible explanations for the discrepancy, we added two panels in Fig. 3 using the $1 \% /$ year $\mathrm{CO}_{2}$-increase experiments carried out by the CMIP3 modeling groups. We similarly applied the S/N EOF analysis to the 20 available models (see Table 1) and define the forced mode using S/N EOF1. The forced time series in the $1 \% /$ year $\mathrm{CO}_{2}$ experiments (not shown) are very similar to a linear increase as in the 21st Century, but the amplitude of increase in North Atlantic SST is similar to that of the 20th Century. The forced regression patterns are shown at the bottom panels of Fig. 3. The precipitation regression pattern in the $1 \% /$ year $\mathrm{CO}_{2}$ model simulations (Fig. 3f) is very similar to that for the 21 st century (Fig. $3 \mathrm{~g}$ ). The similarities suggest that the discrepancies between 20th and 21st centuries are most likely caused by the differing aerosol forcing in the two centuries, rather than by the increased forcing amplitude in the 21st Century.

The seasonal dependence of the precipitation response to external forcing is explored, using regression analysis, in Fig. 4 for northern winter (NDJF) and summer (JJAS) in forced regressions with precipitation.

\section{Regression of $\operatorname{Pr}$ onto Forced Component(JJAS)}

\section{(d) Observations}

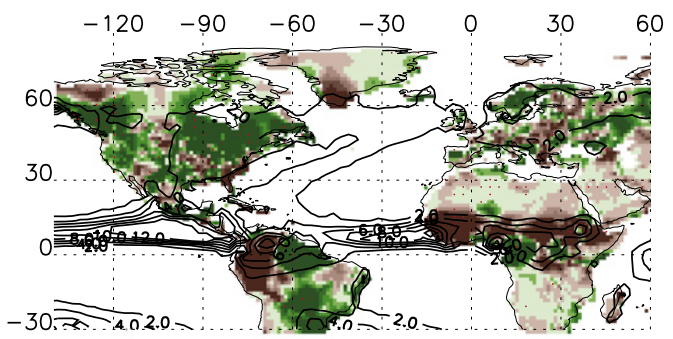

(e) 20th Century

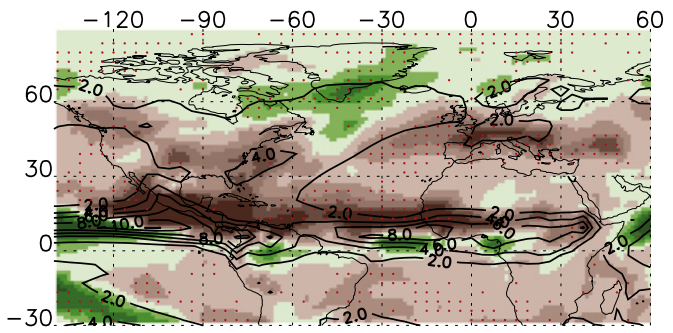

\section{(f) 21 st Century}

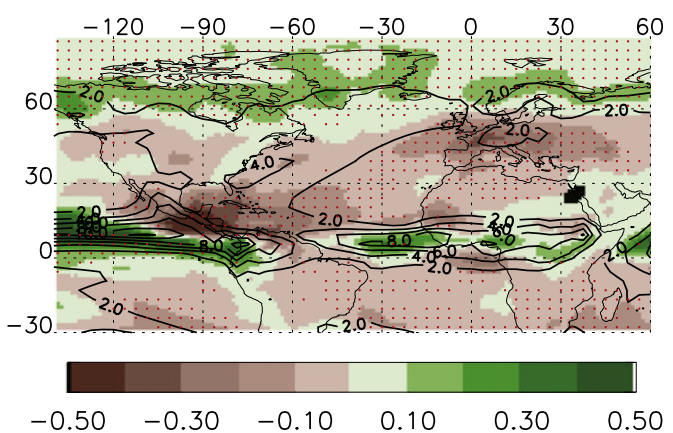

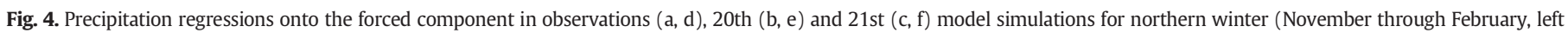
panels) and northern summer (June through September, right panels). Stippling follows the same convention as in Fig. 3. 
In both cases, the $\mathrm{S} / \mathrm{N}$ EOF analysis was first applied to the seasonal mean North Atlantic SST to define the forced time series used for the regression. While the overall precipitation patterns are relatively insensitive to seasons, the subtropical drying signal is more intense and extended further poleward during the corresponding summer season in both hemispheres. In particular, there is a distinctive Sahel drying signal in the Northern summer season, while the drying in Northern winter there is not significant. As in Fig. 3 for the annual mean precipitation, the amplitude of the subtropical drying in the 21st Century in Fig. 4 is much less pronounced compared to that in the 20th Century in CMIP3 model simulations, which is largely attributable to the 20th Century aerosol forcing.

\section{Natural (Internal) AMO}

Several previous studies (e.g. DelSole et al., 2010; Knight, 2009; Ting et al., 2009), as well as Fig. 2 show that the observed North Atlantic SST fluctuations can not be explained by CMIP3 models' estimate of externally forced North Atlantic SST variability. We can further explore whether the CMIP3 models' 20th and 21st Century simulations exhibit internal, unforced decadal to multi-decadal oscillations in addition to the forced response, by looking at each individual model's residual North Atlantic basin-wide averaged, low-pass filtered SST, after subtracting the corresponding model forced component (shown in Fig. 2). All models exhibit internal AMO-like fluctuations that are, as expected, not synchronized in time. The models diverge widely in the time scale that this internal signal displays. Fig. 5 shows the AMO time series for the 5 individual model runs that exhibit the longest time scales (left panels) and the five that display the shortest time scales (right panels). The time scale estimates are based on the lagged autocorrelation function of the residual AMO time series (Ting et al., 2011). The 20th Century observed AMO index is shown in solid black line in both top panels of Fig. 5 as a comparison. It is clear that the model AMO shows a wide range of time scales, ranging from those similar to 20th Century observations with an approximate period of 70 years to those resembling the pattern of low-pass filtered white noise.

Despite the lack of a consistent periodicity in the CMIP3 models internal AMO, Ting et al. (2011) showed that the related-SST pattern in the North Atlantic is rather robust, characterized by a comma-shaped warm SST anomaly associated with the positive phase of the AMO, which extends from the subpolar North Atlantic to subtropical North Atlantic along the eastern part of the basin, with a relative minimum off the U.S. east coast (see Fig. 2 in Ting et al., 2011 as well as color shaded patterns in Fig. 8 of this paper). These typical AMO spatial patterns are also evident in multidecadal averages of de-trended SST in 20th Century observations (Alexander et al., 2014-this volume). We examine here the global patterns of seasonal precipitation associated with the free component of AMO in 20th Century observations, 20th and 21st Century and preindustrial model simulations in Fig. 6 for both northern winter (NDJF) and northern summer (JJAS). Shown in Fig. 6 are the average regression coefficients based on each model's regression coefficients between global precipitation at each grid point and that model's
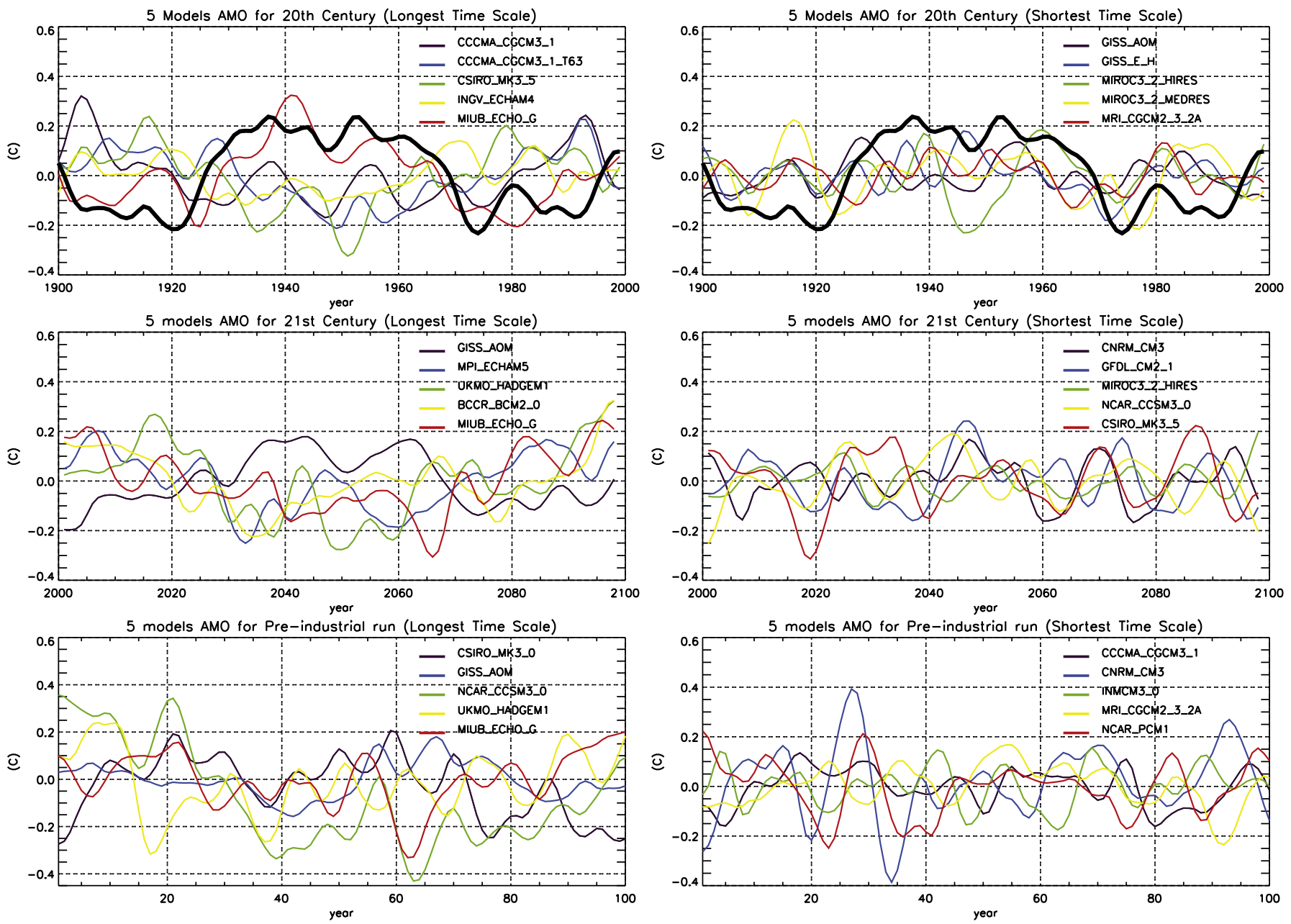

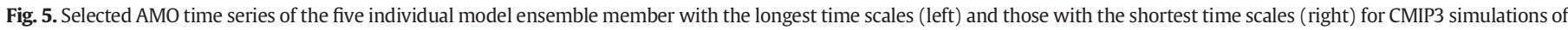

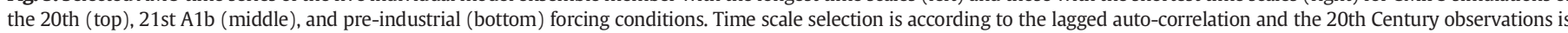
shown in the top panels in solid black line for comparison. 
Regression of Pr onto AMV Index (NDJF)

(a) Observations

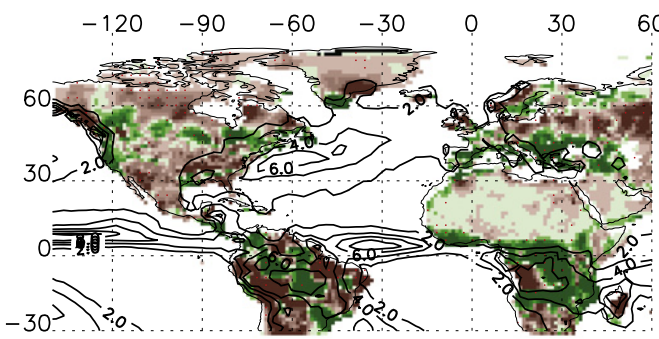

(b) 20th Century

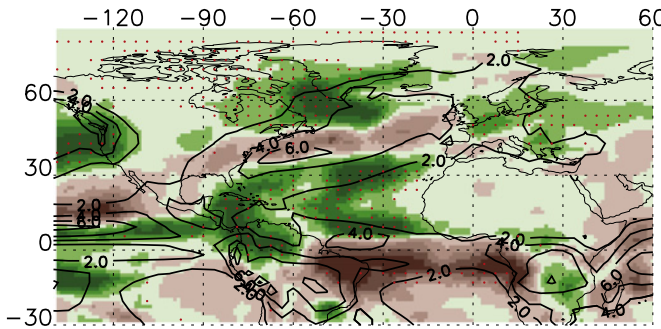

(c) 21st Century

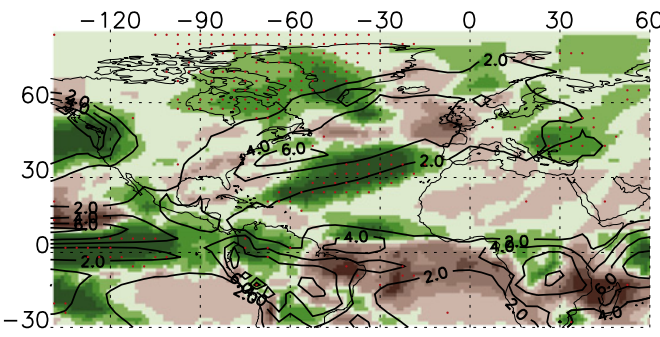

(d) Pre-Industrial

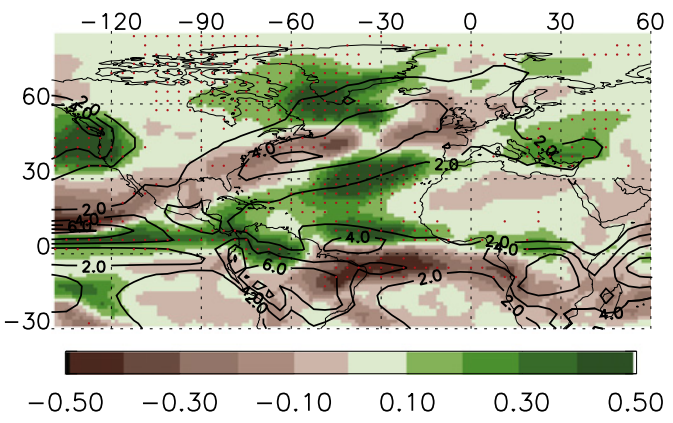

Regression of Pr onto AMV Index (JJAS)

(e) Observations

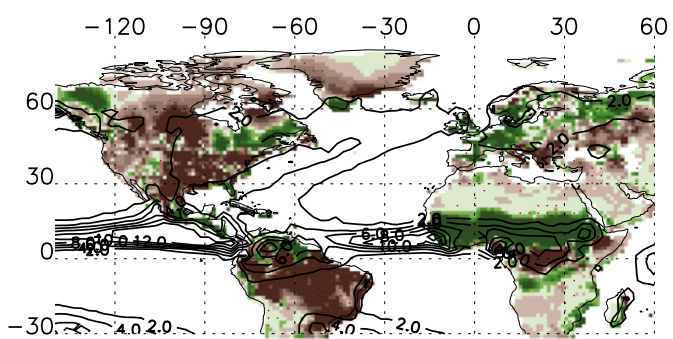

(f) 20th Century

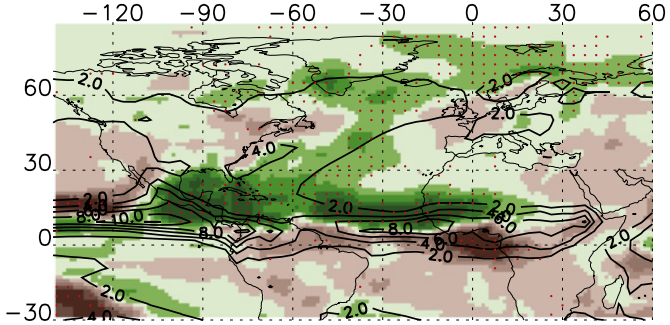

(g) $21 \mathrm{st}$ Century

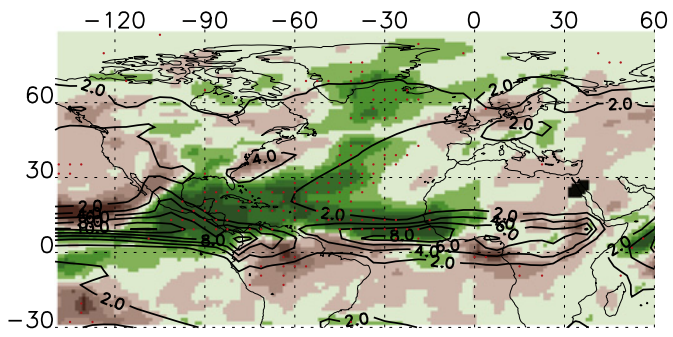

(h) Pre-Industrial

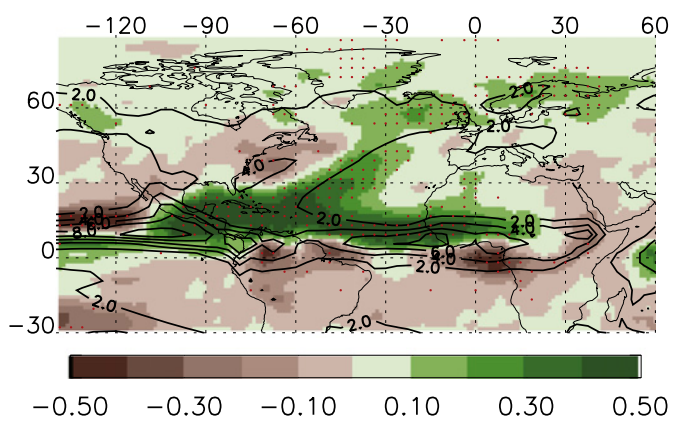

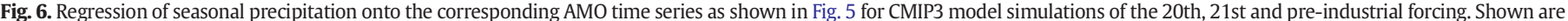

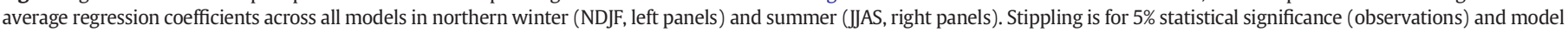

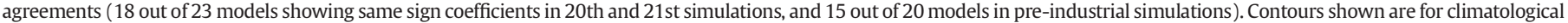
mean rainfall in each case in $\mathrm{mm} /$ day.

corresponding AMO time series as shown in Fig. 5. The contours in Fig. 6 depict the climatological precipitation patterns in each case. The precipitation changes in the tropical Atlantic associated with the warm phase of the AMO are characterized by a northward shift of the Inter-Tropical Convergence Zone (ITCZ, the maximum precipitation zone in climatological rainfall). As discussed in Ting et al. (2011), the ITCZ shift is largely associated with the north-south temperature gradient across tropical Atlantic during the warm phase of the AMO (see Fig. 8).

The global precipitation anomalies associated with AMO have been discussed extensively in the literature (e.g., Enfield et al., 2001; Knight et al., 2006; Kushnir et al., 2010; Seager et al., 2010; Sutton and Hodson, 2005; Ting et al., 2009; Zhang and Delworth, 2006). Fig. 6 confirms many of the previously noted precipitation anomalies associated with the AMO, particularly those in the Sahel, North America, and Northeastern South America. In the models, one can see more clearly that the dominant precipitation signal associated with the AMO is the ITCZ shift in the tropics, resulting in a north-south dipole straddling the ITCZ, with one sign extending from Central America to western Sahel and opposite sign anomalies from South America to South Africa. The pronounced drying signal over North America in both winter and summer associated with AMO warm phase as in 20th Century observations and noted by previous studies (e.g., McCabe et al., 2004), however, is less robust in the models.

There is a clear seasonality associated with the position of the ITCZ in Fig. 6. The Sahel rainfall signal is only present in Northern summer season when the position of the ITCZ is further north, while the drying over 
northwestern South America and western South Africa is much more pronounced during northern winter when the ITCZ is located farther south. Over the North Atlantic, precipitation generally increases during the warm phase of the AMO. During the winter, there is a clear enhancement of precipitation in the central North Atlantic that indicates a southward shift of the Atlantic storm tracks in all CMIP3 simulations. This feature is also present in northern summer to a lesser extent. The change in atmospheric circulation associated with the AMO will be discussed further below.

To increase our understanding of how the AMO impacts the atmosphere and vice versa, we examine the sea level pressure (SLP), surface wind, and $500 \mathrm{mb}$ geopotential height patterns associated with the AMO. We use the 20th Century reanalysis (Compo et al., 2011) for the 20th Century atmospheric observations. Fig. 7 shows the

\section{Regression of SLP onto AMV Index (NDJF)} (a) Observations

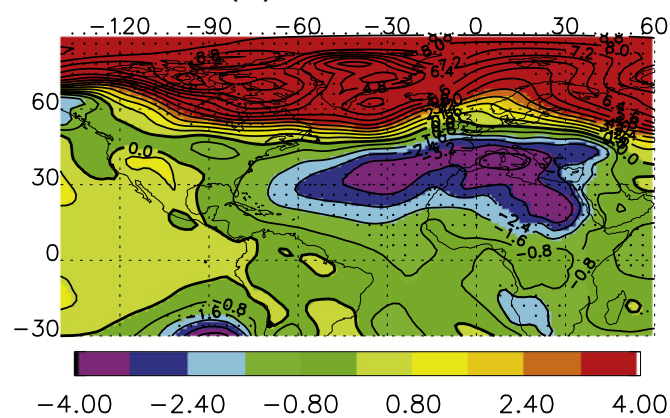

(b) 20th Century

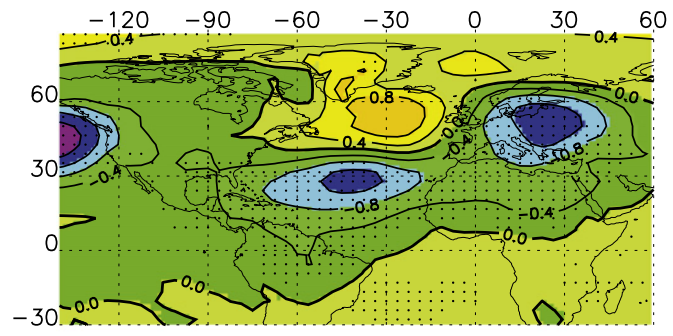

(c) 21 st Century

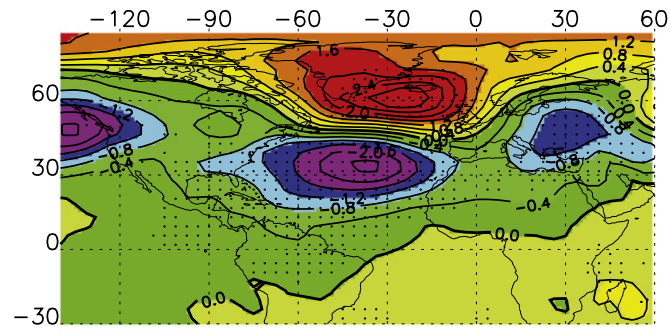

(d) Pre-Industrial

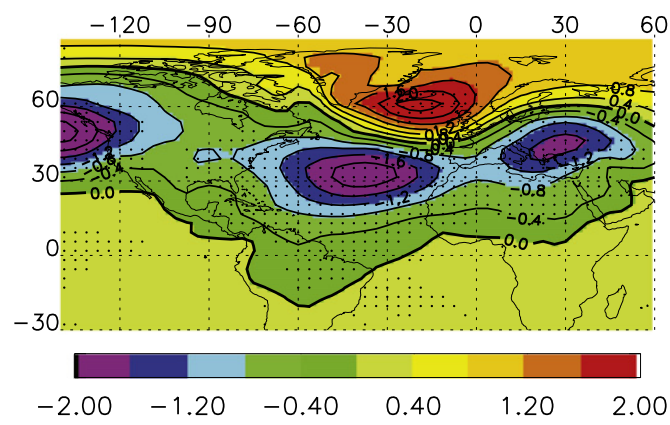

SLP regression for northern winter (left panels) and summer (right panels) for observations (top panels) and CMIP3 simulations of the 20th, 21st, and pre-industrial forcing. The northern winter regression pattern displays a zone of anomalous high pressure north of $\sim 60^{\circ} \mathrm{N}$ and low pressure in the Mediterranean region and the subtropical North Atlantic, when the AMO is in its warm phase. This pattern bears resemblance to the negative phase of the North Atlantic Oscillation (NAO, Hurrell et al., 2003). The models' AMO-associated SLP patterns in northern winter roughly agree with observations, but displays a rather distinct wave train pattern over the Atlantic and European sector originating from the tropical Atlantic, with a low over the tropical Atlantic, a high southeast of Greenland, and another low over the Mediterranean Sea. The wave train pattern in models are robust for all forcing scenarios, although the amplitude differ considerably, with the

\section{Regression of SLP onto AMV Index(JJAS)}

\section{(e) Observations}

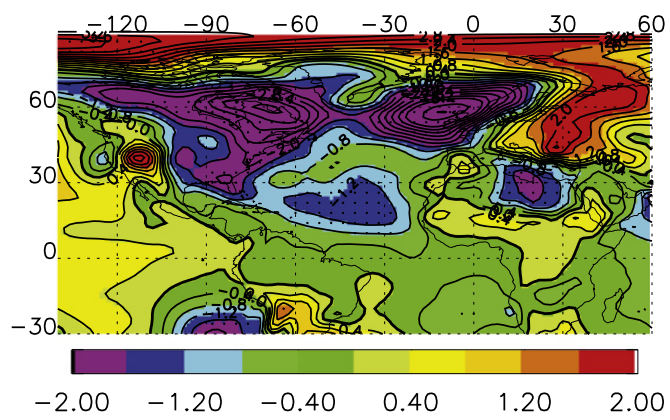

(f) 20th Century

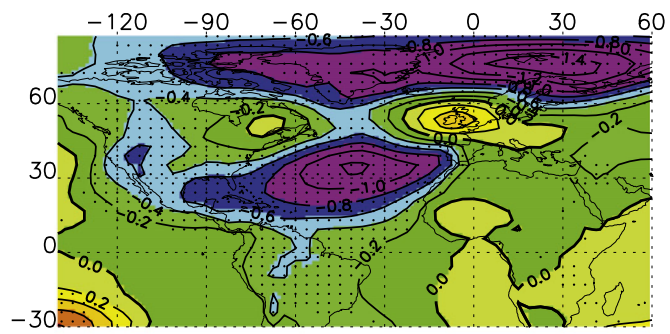

(g) 21 st Century

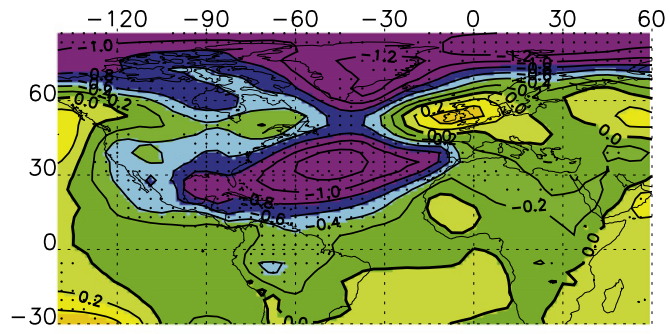

(h) Pre-Industrial

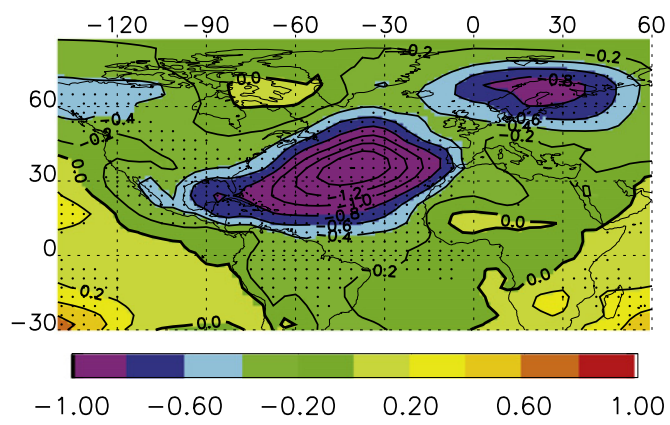

Fig. 7. Same as Fig. 6, but for sea level pressure. Note the different contour interval and color scales for 20th Century observations (top panels) and the CMIP3 models. 
20th Century pattern less than half the amplitude of the 21st and the pre-industrial simulations. The cause of the amplitude discrepancy is mainly from the large number of ensemble members for the 20th Century (75, see Table 1 ). When only one ensemble member per model were used for the 20th Century, the amplitude is much closer to the other cases. The Atlantic wave train pattern in northern winter is consistent with the notion of atmospheric Rossby wave response to tropical Atlantic heating (Hoskins and Karoly, 1981). During northern summer, the AMO-related SLP patterns are dominated by a low center over the subtropical North Atlantic, consistent with the atmospheric response to tropical Atlantic heating (Kushnir et al., 2010) in both models and observations. The agreement between models and observations, however, is not very strong north of $30 \mathrm{~N}$. The discrepancy between model and observations could be the result of the short observational record and the relatively small signal-to-noise ratio in the mid and high latitudes SLP fields.

Regression of Surfoce Wind onto AMV Index (NDJF)

(a) Observations
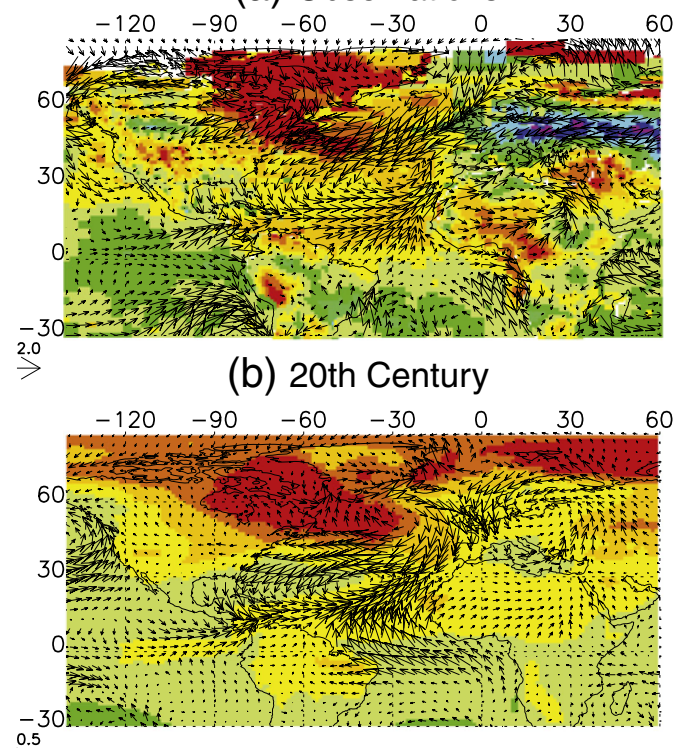

(c) 21 st Century

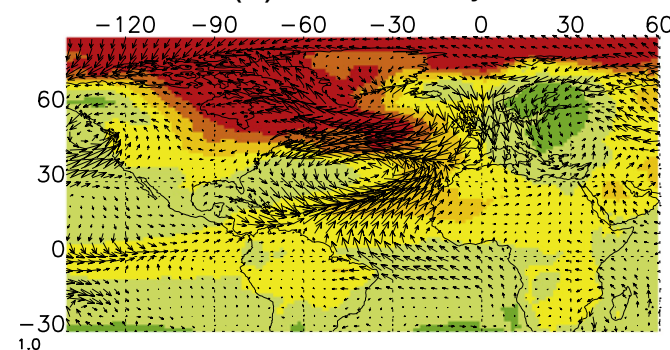

(d) Pre-Industrial

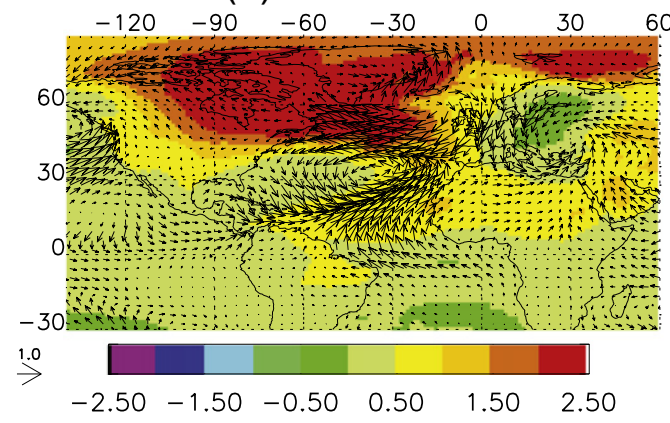

The dominance of the subtropical low-pressure response in both winter and summer associated with AMO warm-phase is clearly seen in Fig. 8, which shows the counterclockwise surface wind circulation (vectors) around the low-pressure center in the tropical Atlantic following the approximate geostrophic relation. Also shown in Fig. 8 is the AMO sea surface temperature over the oceans and surface air temperature over land shaded in color. These surface wind anomalies are in general opposing the climatological surface wind, thus reducing the climatological surface wind in both the tropics and midlatitudes except south of equator in the Atlantic. The warm SST pattern in the tropical and subtropical North Atlantic, on the other hand, is consistent with reduced trade wind in the tropics and reduced upwelling along the west coast of Africa due to the anomalous northward flow there. While the mechanisms of AMO is not the focus of this study, the results in Figs. 7 and 8 do suggest that positive ocean-atmosphere interactions may be responsible for the AMO SST pattern in the tropics and subtropics.

Regression of Surfoce Wind onto AMV Index (JJAS)

(e) Observations

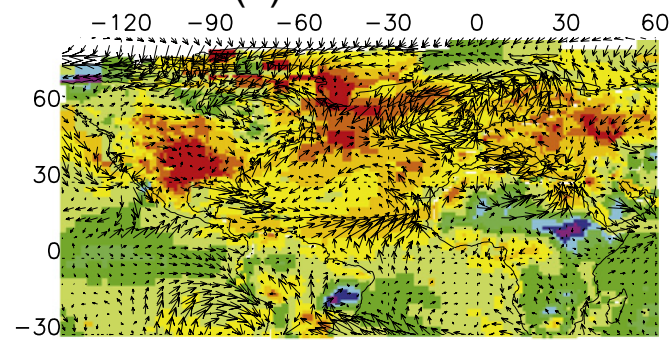

(f) 20th Century

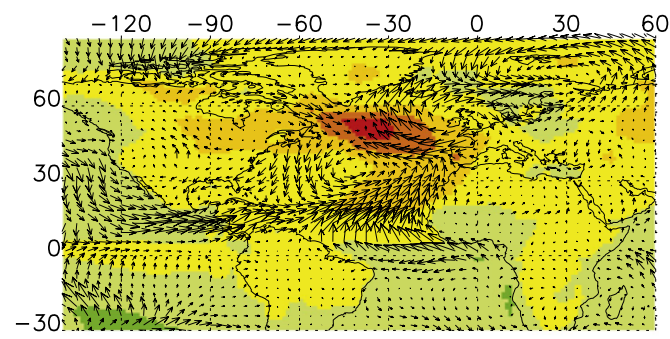

(g) $21 \mathrm{st}$ Century

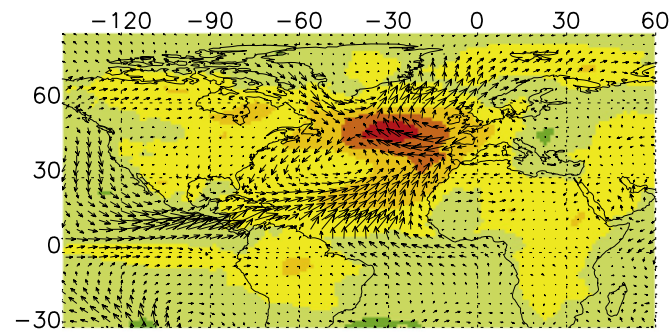

(h) Pre-Industrial

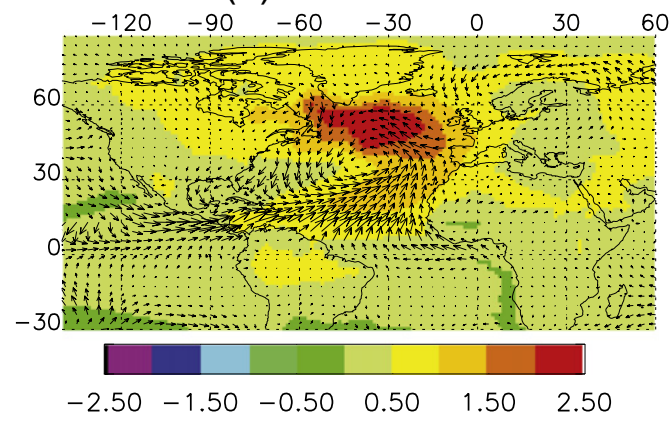

Fig. 8. Same as Fig. 6, but for surface wind (vectors) and surface temperature (shading) over the North Atlantic domain. 
The upper tropospheric responses associated with AMO warm phase are shown in Fig. 9 using the $500 \mathrm{mb}$ geopotential height regressed onto the AMO index. Fig. 9 confirms the association with the negative phase of the NAO in northern winter as indicated by the SLP. It also indicates a weakening of the Atlantic jet stream and associated storm track activity at $40^{\circ} \mathrm{N}$, which is consistent with the reduced storm track precipitation in Fig. 6. For the northern summer season, however, there is very little agreement between observations and models. The models do indicate that the positive AMO phase is associated with robust anticyclonic anomalies over eastern North America and over Western Europe, which may suggest enhanced blocking during the summer in these regions, increased subsidence and reduced precipitation.

\section{Summary}

In this paper we explored the patterns of forced and natural North Atlantic multidecadal SST variability in observations and in coupled models integrated under different anthropogenic forcing scenarios. For the models we used the CMIP3-ensemble simulations of the pre-industrial climate, the 20th century, realistic forcing simulations (including anthropogenic and natural), and 21st century simulations forced under IPCC AR4 scenario A1B. Our method of analysis employed the signal-to-noise maximizing EOF technique, which optimally separated free internal variability and externally forced variability. In this procedure, we first estimated the forced component in each forcing scenario and found the time series and pattern of forced variability. We
Regression of GH500 onto AMV Index(NDJF)

(a) Observations

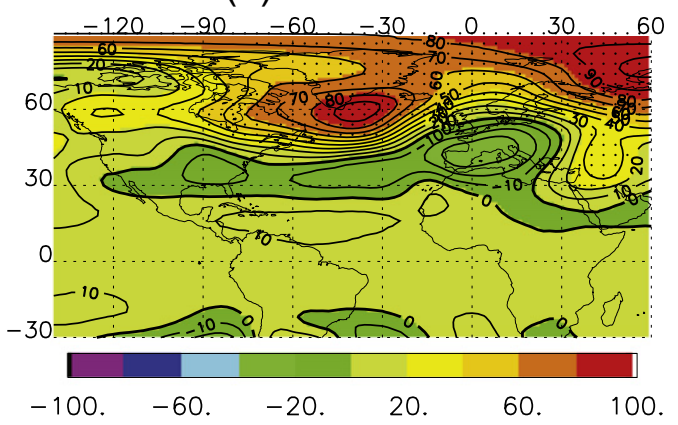

(b) 20th Century

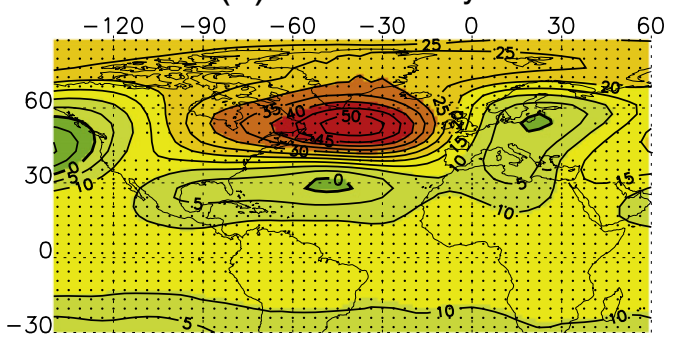

(c) $21 \mathrm{st}$ Century

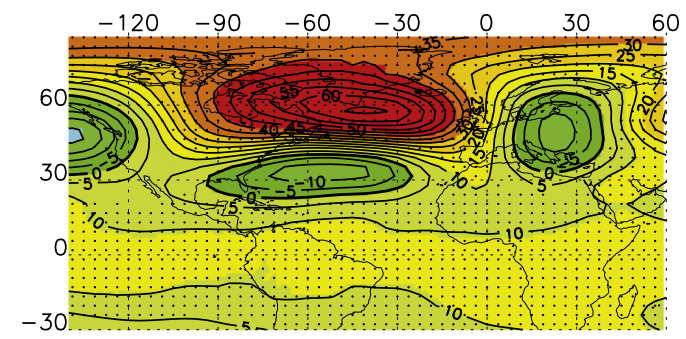

(d) Pre-Industrial

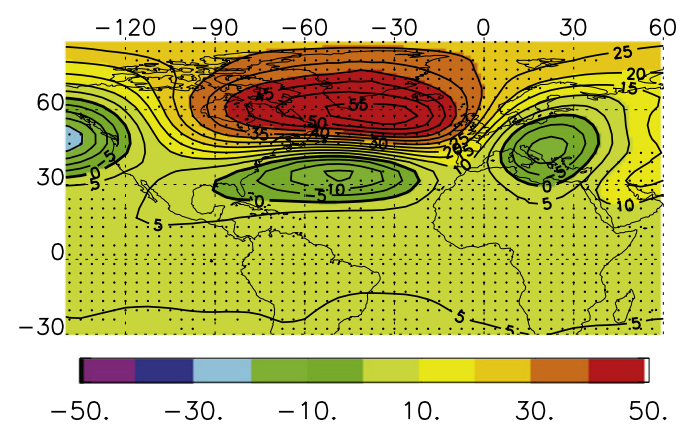

\section{Regression of GH500 onto AMV Index(JJAS)}

\section{(e) Observations}

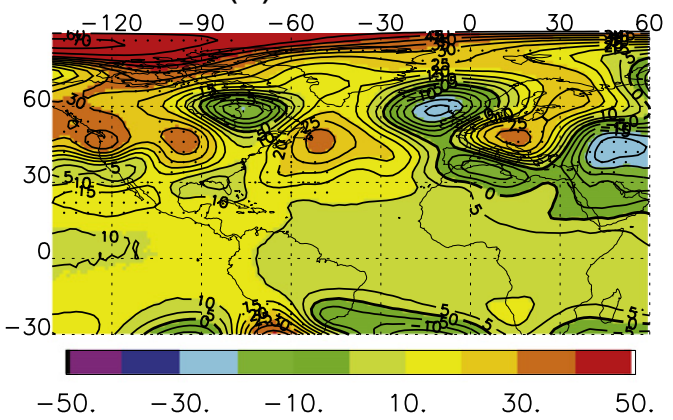

(f) 20th Century

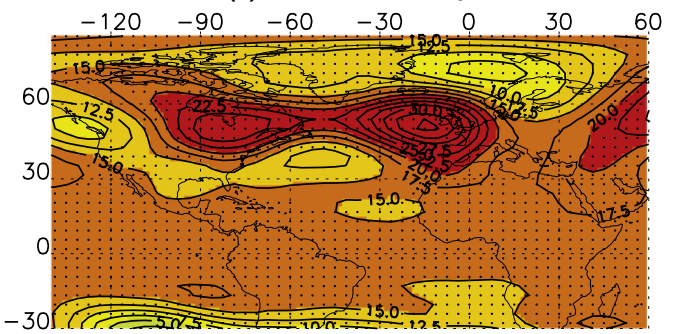

(g) 21 st Century

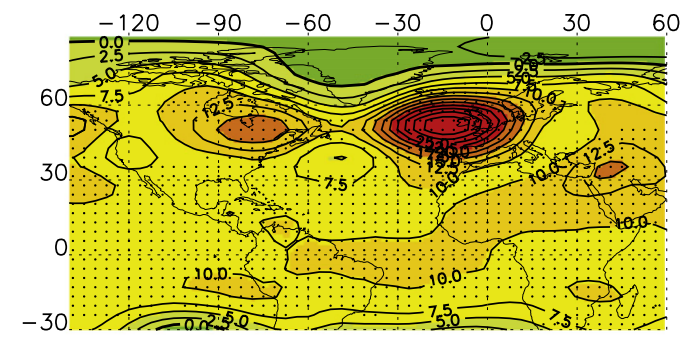

(h) Pre-Industrial

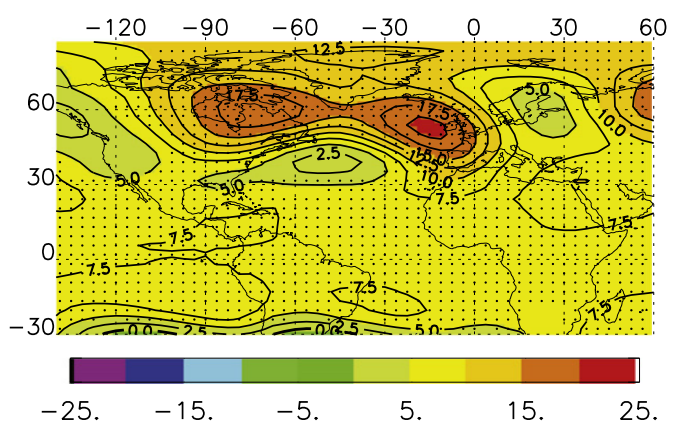

Fig. 9. Same as Fig. 6, but for 500 mb geopotential height. Note the different contour interval and color scales for 20th Century observations (top panels) and the CMIP3 models. 
then subtracted the space-time dependent forced component from the full datasets and from those obtained the unforced or internal component. We concluded that the observed multi-decadal variability of North Atlantic SST during the 20th Century cannot be explained fully by the radiative forcing (anthropogenic and natural), consistent with previous studies (DelSole et al., 2010; Knight, 2009; Ting et al., 2009). Furthermore, the spatial structures of the forced and the internal variability of North Atlantic SST differed considerably, both within the North Atlantic Basin and globally. While the forced component displayed a positive trend in time that was spatially consistent with an almost global-wide warming of surface temperature, the internal component, in contrast, was oscillating in time and spatially was largely confined to the North Atlantic basin. Locally in the North Atlantic, the two components also differed significantly with the forced one showing a stronger warming in South Atlantic than in the North and thus a northward gradient in SST across the tropical Atlantic, while the warm phase of the internal AMO had a basin-wide warming in North Atlantic and weak cooling in South Atlantic, thus a southward gradient across tropical Atlantic. The AMO warm phase will thus weaken the northward SST gradient due to anthropogenic forcing in the tropical Atlantic, while in the AMO negative phase, it will enhance the northward SST gradient due to global warming. In the subpolar North Atlantic, the forced global warming displayed a distinctive cooling off the South coast of Greenland, while the positive phase of AMO had an intensified warming at the same location. The model expressions of internal variability showed a large degree of consistency under different forcing scenarios, as well as agreement with 20th Century observed pattern, despite the varying degree of greenhouse and aerosol forcing. This suggests that our analysis methods did a good job in separating the two types of variability, forced and internal.

The precipitation patterns associated with the forced and natural component of North Atlantic SST variability differed significantly from one another. While the forced precipitation signal showed a widespread subtropical drying trend and a high latitude wetting trend, consistent with results based on a straight forward multi-model average (Solomon et al., 2007), the AMO associated rainfall patterns pointed at a shift of Atlantic ITCZ north of the climatological position (during the warm phase of the AMO) and south (during the cold phase of the AMO). The warm (cold) AMO phase was thus associated with enhanced (reduced) rainfall in the tropical North Atlantic, including the Sahel and Central America, and drying (wetting) in northeastern South America and northwestern South Africa. There was a general drying trend in North America associated with the warm phase of AMO, but this result was less robust across models.

The most dominant atmospheric circulation features associated with the AMO was a low pressure center over the subtropical North Atlantic and the Mediterranean in both winter and summer, consistent with the simple model response to enhanced tropical Atlantic heating (Kushnir et al., 2010). The AMO surface wind anomaly associated with the subtropical low pressure anomaly center suggested that the underlying warm SST pattern was forced by the atmosphere and the reduction in the surface heat flux from the ocean to the atmosphere, thus implying a positive ocean-atmosphere interaction in the formation of the tropical and subtropical AMO SST pattern. There was also an indication of warm AMO strongly associated with an SLP pattern that resembled the negative NAO, thus reduced subtropical jet and storm activity, particularly in the winter.

Although internal ocean-atmosphere positive feedback may have been responsible for the AMO SST pattern in the subtropical and tropical North Atlantic, two important questions remain unanswered. The first question is what determines the multi-decadal time scale and the second one is what causes the subpolar AMO SST pattern. The linkage between fluctuations of the Atlantic meridional overturning circulation and the AMO SST pattern and the physical mechanisms leading to the AMO SST pattern in both models and observations will be explored in future studies.

\section{Acknowledgments}

The research is supported by NOAA grants NA08OAR4320912, NA10OAR4310124 and NA10OAR4310137, and NSF grant ATM 0739983. We would like to thank the Global Decadal Hydroclimate (GloDecH) group at Lamont and Columbia for their comments.

\section{References}

Alexander, M.A., Kilbourne, K.H., Nye, J., 2014. Climate variability during warm and cold phases of the Atlantic Multidecadal Oscillation (AMO) 1871-2008. J. Mar. Syst. 133, 14-26 (this volume).

Allen, M.R., Smith, L.A., 1997. Optimal filtering in singular spectrum analysis. Phys. Lett. 234, 419-428.

Booth, B.B.B., Dunstone, N.J., Halloran, P.R., Andrews, T., Bellouin, N., 2012. Aerosols implicated as a prime driver of twentieth-century North Atlantic climate variability. Nature 484, 228-232.

Compo, G.P., Whitaker, J.S., Sardeshmukh, P.D., Matsui, N., Allan, R.J., Yin, X., Gleason, B.E., Vose, R.S., Rutledge, G., Bessemoulin, P., Brönnimann, S., Brunet, M., Crouthamel, R.I., Grant, A.N., Groisman, P.Y., Jones, P.D., Kruk, M., Kruger, A.C., Marshall, G.J., Maugeri, M., Mok, H.Y., Nordli, Ø., Ross, T.F., Trigo, R.M., Wang, X.L., Woodruff, S.D., Worley, S.J., 2011. The twentieth century reanalysis project. Q. J. Roy.Meteorol. Soc. 137, 1-28. http://dx.doi.org/10.1002/qj.776.

DelSole, T. Tippett, M.K., Shukla, J., 2010. A significant component of unforced multidecadal variability in the recent acceleration of global warming. J. Climate. http://dx.doi.org/10.1175/2010JCLI3659.1.

Delworth, T.L., Mann, M.E., 2000. Observed and simulated multidecadal variability in the Northern Hemisphere. Clim. Dyn. 16, 661-676.

Enfield, D.B., Mestas-Nunez, A.M., Trimble, P.J., 2001. The Atlantic Multidecadal Oscillation and its relation to rainfall and river flows in the continental U.S. Geophys. Res. Lett. 28, 2077-2080.

Gray, S.T., Graumlich, L.J., Betancourt, J.L., Pederson, G.T., 2004. A tree-ring based reconstruction of the Atlantic Multidecadal Oscillation since 1567 AD. Geophys. Res. Lett. 31. http://dx.doi.org/10.1029/2004GL019932.

Hansen, J., Ruedy, R., Sato, M., Lo, K., 2010. Global surface temperature change. Rev. Geophys. 48, RG4004. http://dx.doi.org/10.1029/2010RG00345.

Held, I.M., Soden, B.J., 2006. Robust responses of the hydrological cycle to global warming. J. Climate 19, 5686-5699.

Holland, M.M., Bitz, C.M., 2003. Polar amplification of climate change in coupled models. Clim. Dyn. 21, 221-232.

Hoskins, B.J., Karoly, D.J., 1981. The steady linear response of a spherical atmosphere to thermal and orographic forcing. J. Atmos. Sci. 38, 1179-1196.

Hurrell, J., Kushnir, Y., Visbeck, M., Ottersen, G., 2003. An overview of the North Atlantic Oscillation. In: Hurrell, J.W., Kushnir, Y., Ottersen, G., Visbeck, M. (Eds.), The North Atlantic Oscillation: climatic significance and environmental impact. Geophys. Monogr. Ser., 134, 279 pp. AGU, Washington, D. C., pp. 1-35. http://dx.doi.org/10.1029/GM134.

Knight, J.R., 2009. The Atlantic Multidecadal Oscillation inferred from the forced climate response in coupled general circulation models. J. Climate 22, 1610-1625.

Knight, J.R., Folland, C.K. Scaife, A.A., 2006. Climate impacts of the Atlantic Multidecadal Oscillation. Geophys. Res. Lett. 33, L17706. http://dx.doi.org/10.1029/2006GL026242.

Knudsen, M.F., Seidenkrantz, M.-S., Jacobsen, B.H., Kuijpers, A., 2011. Tracking the Atlantic Multidecadal Oscillation through the last 8,000 years. Nat. Commun. 2, 178. http:// dx.doi.org/10.1038/ncomms1186.

Kushnir, Y., Seager, R., Ting, M., Naik, N., Nakamura, J., 2010. Mechanisms of tropical Atlantic SST influence on North American precipitation variability. J. Climate. http:// dx.doi.org/10.1175/2010JCLI3172.1.

Mann, M.E., Emanuel, K., 2006. Atlantic hurricane trends linked to climate change. EOS Trans. Am. Geophys. Union 87, 233-244.

McCabe, G.J., Palecki, M.A., Betancourt, J.L., 2004. Pacific and Atlantic Ocean influences on multi-decadal drought frequency in the United States. Proc. Natl. Acad. Sci. U. S. A. 101, 4136-4141. http://dx.doi.org/10.1073/pnas.0306738101.

Meehl, G.A., Washington, W.M., Erickson III, D.J., Briegleb, B.P., Jaumann, P.J., 1996. Climate change from increased $\mathrm{CO}_{2}$ and direct and indirect effects of sulfate aerosols. Geophys. Res. Lett. 23, 3755-3758.

Meehl, G.A., Washington, W.M., Ammann, C.M., Arblaster, J.M., Wigley, T.M.L., Tebaldi, C., 2004. Combinations of natural and anthropogenic forcings in 20th century climate. J. Climate 17, 3721-3727.

Mitchell, T.D., Jones, P.D., 2005. An improved method of constructing a database of monthly climate observations and associated high-resolution grids. Int. J. Climatol. 25, 693-712. http://dx.doi.org/10.1002/joc.1181.

Rayner, N.A., Parker, D.E., Horton, E.B., Folland, C.K., Alexander, L.V., Rowell, D.P., Kent, E.C., Kaplan, A., 2003. Global analyses of sea surface temperature, sea ice, and night marine air temperature since the late nineteenth century. J. Geophys. Res. 108 (D14), 4407. http://dx.doi.org/10.1029/2002JD002670.

Reynolds, R.W., Rayner, N.A., Smith, T.M., Stokes, D.C., Wang, W., 2002. An improved in situ and satellite SST analysis for climate. J. Climate 15, 1609-1625. http://dx.doi.org/ $10.1175 / 1520-0442$.

Russell, G.L., Rind, D., 1999. Response to $\mathrm{CO}_{2}$ transient increase in the GISS coupled model: regional coolings in a warming climate. J. Climate 12, 531-539.

Schlesinger, M.E., Ramankutty, N., 1994. An oscillation in the global climate system of period 65-70 years. Nature 367 (6465), 723-726.

Seager, R., Naik, N., Baethgen, W., Robertson, A., Kushnir, Y., Nakamura, J., Jurburg, S., 2010. Tropical oceanic causes of interannual to multidecadal variability in southeast South America over the past century. J. Climate 23, 5517-5539. 
Solomon, S., Oin, D., Manning, M., Marquis, M., Averyt, K., Tignor, M.M.B., Miller Jr., H.L. Chen, Z. (Eds.), 2007. Climate Change 2007: The Physical Science Basis. Cambridge University Press (996 pp.).

Sutton, R.T., Hodson, D.L.R., 2005. Atlantic Ocean forcing of North American and European summer climate. Science 309, 115-118. http://dx.doi.org/10.1126/science.1109496.

Ting, M., Kushnir, Y., Seager, R., Li, C., 2009. Forced and internal twentieth-century SST in the North Atlantic. J. Climate 22, 1469-1481.

Ting, M., Kushnir, Y., Seager, R., Li, C., 2011. Robust features of Atlantic multi-decadal variability and its climate impacts. Geophys. Res. Lett. 38, L17705. http://dx.doi.org/ 10.1029/2011GL048712.
Wood, R.A., Keen, A.B., Mitchell, J.F.B., Gregory, J.M., 1999. Changing spatial structure of the thermohaline circulation in response to atmospheric $\mathrm{CO}_{2}$ forcing in a climate model. Nature 399, 572-575.

Zhang, R., Delworth, T.L., 2006. Impact of Atlantic multidecadal oscillations on India/Sahe rainfall and Atlantic hurricanes. Geophys. Res. Lett. 33, L17712. http://dx.doi.org/ 10.1029/2006GL026267.

Zhang, R., Delworth, T.L., Sutton, R., Hodson, D.L.R., Dixon, K.W., Held, I.M., Kushnir, Y., Marshall, J., Ming, Y., Msadek, R., Robson, J., Rosati, A.J., Ting, M., Vecchi, G.A., 2013. Have aerosols caused the observed Atlantic Multidecadal Variability? J. Atmos. Sci. http://dx.doi.org/10.1175/JAS-D-12-0331.1. 